\title{
METAFORE O SMRTI I UMIRANJU U ŠPANSKOM I SRPSKOM JEZIKU
}

Cilj rada je da osvetli fenomen smrti u španskoj i srpskoj tradiciji i kulturi poređenjem metafora o smrti i umiranju. Rad se oslanja na postulate kognitivne lingvistike i teorije konceptualne metafore. Analiza metafora o smrti i umiranju upućuje na to da su navedena metaforička mapiranja vezana za pojam smrti istovremeno i mapiranja utemeljena na hrišćanskom sistemu verovanja (verovanja u besmrtnost, tj. večni život, postojanje raja i pakla, Sudnji dan, Boga kao Stvaraoca koji je na nebu itd.). Upravo ova verovanja pružaju osnovu za niz metaforičkih preslikavanja, koja su zajednička obama jezicima, tj. narodima, i nalaze se u osnovi izraza: SMRT JE VEČNI ŽIVOT, SMRT JE UNIJA/SJEDINJAVANJE SA BOGOM, SMRT JE SAN/ODMOR, SMRT JE PUTOVANJE/ODLAZAK i SMRT JE KRAJ. S obzirom na to da oba naroda pripadaju evropskom kontekstu i hrišćanskoj tradiciji i kulturi, ostaje otvoreno pitanje o postojanju univerzalnog karaktera metaforičkih mapiranja koja smo pronašli u obama jezicima. Buduća istraživanja na ovu temu trebalo bi da iznedre kontrastivne studije koje bi ove jezike poredile sa jezicima koji ne pripadaju judeohrišćanskoj tradiciji.

Ključne reči: metafora, idiomatski izraz / frazem / frazeologizam, smrt, religija, španski jezik, srpski jezik.

\section{UVOD}

„Svet hoće da se obnovi. Miriše na smrt. Ništa novo ne dolazi bez smrti.”

(Herman Hese)

Smrt je najveća misterija života. Njena neizbežnost je tokom istorije bila izvor čuda, straha, nade i zbunjenosti, a ljudi su jedina vrsta koja je svesna neizbežnosti smrti (Wendell Moller, 2003: 871). Smrt predstavlja neodvojivi deo ljudskog života i taj fenomen zaokupljao je čoveka od najranijih dana. To je pojava o kojoj se promišljalo još od antičkih vremena, a svaka tradicija gradi verovanja,

*ivana.georgijev@ff.uns.ac.rs 
mitove i obrede vezane za fenomen smrti u skladu sa svojim istorijskim, religioznim i kulturološkim osobenostima (Drobnjak-Gudurić, 2011: 237). Kroz istoriju religija i smrt bile su neraskidivo povezane, a smrt se često smatra jednim od osnovnih pokretača religioznosti. Strah od smrti, odnosno želja da se prevaziđu granice ovog jednog ,telesnog” života koji nam je dat, tj. da se nastavi besmrtno postojanje, prema ovakvom mišljenju, u osnovi je religijskog pogleda na svet (Kovačević-Sinani, 2014: 1055-1056).

Cilj ovog rada jeste da osvetli fenomen smrti u španskoj i srpskoj tradiciji i kulturi poređenjem metafora o smrti i umiranju, kao i da otkrije postojanje konceptualne organizacije koja bi bila shvaćena kao osnova korišćenja različitih metaforičkih izraza za smrt i umiranje. Analizom španskog i srpskog korpusa imamo za cilj da identifikujemo metaforička preslikavanja (mapiranja) u ovim dvama jezicima, tj. da uočimo načine metaforičke konceptualizacije fenomena smrti. Imajući u vidu da srpski narod pripada krugu evropskih naroda sa hrišćanskom tradicijom (najvećim delom pravoslavne veroispovesti), kao i da španska zajednica pripada evropskim narodima hrišćanske katoličke tradicije, polazimo od pretpostavke da će zajednička, hrišćanska tradicija u kontrastivnoj analizi metafora o smrti i umiranju ukazati na poklapanja i sličnosti u načinu konceptualizacije ovog fenomena, koji je tokom istorije bio pod velikim uticajem religije.

\section{TEORIJSKI I METODOLOŠKI OKVIR}

Rad se oslanja na postulate kognitivne lingvistike i teorije konceptualne metafore (engl. Conceptual Metaphor Theory), koju su razvili Lejkof i Džonson (Lakoff-Johnson, 2003 [1980]). Kako navode ovi uticajni naučnici u oblasti kognitivne lingvistike (Lakoff-Johnson, 2003 [1980]; Johnson, 1987; Lakoff, 1987; Lakoff, 1994), čini se da je ljudska sposobnost da konceptualizuje i razume svet oko sebe u suštini pitanje ljudskog iskustva (percepcije, motoričkih aktivnosti, kulturnih praksi) i mašte (metafore, metonimije, slikovne šeme).

Metafora u kognitivnoj lingvistici predstavlja glavni mehanizam putem kojeg razumemo apstraktne pojmove i koji nam omogućava da apstraktno razmišljamo, tako što nam pruža način da razumemo pojmove koje ne možemo da vidimo ili da opipamo. Kako navodi Klikovac (2004: 14), apstraktne domene svog iskustva razumemo na osnovu iskustva sa fizičkim svetom, a metafore su naše osnovno sredstvo za razumevanje tih apstraktnih iskustava. Koristimo izvorni konceptualni domen (engl. source domain) da bismo bolje razumeli ciljni konceptualni domen (engl. target domain) (Lakoff-Johnson, 2003 [1980]), pa se 
tako metafora sastoji od izvornog i ciljnog domena: izvorni je više fizička, a ciljni više apstraktna vrsta domena (Kövecses, 2005). Mehanizam metafore zasnovan je na preslikavanju čulno saznatljivog i dobro poznatog domena na drugi domen, koji je apstraktan (Klikovac, 2004: 11-12).

Zajedničko ljudsko iskustvo ima veliki uticaj na oblikovanje metaforičkih preslikavanja koja postoje u jeziku. Upravo to i jeste razlog postojanja mnogih konceptualnih metafora koje možemo smatrati univerzalnim, ili potencijalno univerzalnim (Kövecses, 2015: 6). Kevečeš navodi da se konceptualne metafore mogu zasnivati na dvema (pretežno univerzalnim) stvarima: telesnom iskustvu i (relativnom) kulturnom iskustvu (Kövecses, 2015: 95), a ljudsko telo idealan je izvorni domen, jer ga dobro poznajemo (Kövecses, 2010: 18). Mi interpretiramo sopstveno fizičko iskustvo u skladu sa kulturnim pretpostavkama, vrednostima i stavovima, jer svako je iskustvo prožeto kulturom. To znači da mi doživljavamo sopstveni svet u skladu sa time kako naša kultura oblikuje naša iskustva (LakoffJohnson, 2003 [1980]: 57). U kognitivnoj lingvistici pojmovi „telesno iskustvo” (engl. bodily experience) i „ljudsko utelovljenje” (engl. human embodiment) zauzimaju važno mesto. Koncept utelovljenja povezan je sa našim kolektivnim biološkim kapacitetima i našim fizičkim i društvenim iskustvima. Zbog toga i načini konceptualizacije proizilaze iz naših telesnih iskustava i povezuju se sa njima (Lakoff, 1987: 267).

Tema smrti nalazi svoje mesto u kognitivnoj lingvistici jer smrt je jedna od pojava koje najviše zaokupljaju čovekovu pažnju, mada o njoj istovremeno i ne želimo previše da razmišljamo. Od trenutka rođenja započinje proces starenja, pa je smrt neminovna i neizbežna pojava za sva ljudska bića (Opašić-Gregorović, 2010: 56). Svi govorimo o smrti metaforično upravo otuda što nemamo neposrednog iskustva sa vlastitom smrću, pa razvijamo metafore koje pokušavaju da savladaju tu prazninu neiskustva (Thomas, 2007, prema Kuljić, 2014: 9). Strah od smrti nalazi se u osnovi religijskih učenja i želje da se prevaziđu granice „telesnog” života, koji nam je, kao živim bićima, podaren, tj. da se nastavi besmrtno postojanje nakon telesne smrti. Religija zbog toga ima važno mesto kada je način poimanja smrti i razmišljanja o njoj u pitanju (Kovačević-Sinani, 2014: 1055-1056). Kako navodi Palajsa-Backović (2012: 48), pozitivan stav prema umiranju i odlasku na drugi svet u prošlosti je dominirao zahvaljujući uticaju crkve i pobožnosti društvene zajednice.

Pod pretpostavkom da su hrišćanska uverenja uticala na načine konceptualizacije smrti i umiranja u srpskom i španskom društvu, u narednom delu rada izložena je analiza španskih i srpskih metafora o smrti i umiranju, s posebnim osvrtom na religijski, tačnije hrišćanski, aspekt. Građa je prikupljena iz opštih i frazeoloških rečnika španskog i srpskog jezika i digitalnih izvora. Ističemo da 
poređenje metafora nije vršeno s ciljem da se pronađu ekvivalenti za svaku od njih, već je u radu pažnja usmerena na uočavanje metafora koje se u srpskom i španskom jeziku koriste da bi se govorilo o smrti. Korpus obuhvata 24 jezička izraza, tj. frazema, na srpskom i 34 na španskom jeziku.

\section{ŠPANSKE I SRPSKE METAFORE O SMRTI I UMIRANJU}

Analiza španskih i srpskih metafora o smrti i umiranju ukazala je na postojanje brojnih metafora koje se zasnivaju na sistemu verovanja u hrišćanskoj tradiciji, tj. na nekim od osnovnih hrišćanskih uverenja, kao što su:

- postojanje života nakon smrti, tj. uverenje o besmrtnosti

Antropološki gledano, čovek nije spreman da fizičku smrt prihvati kao odlazak u ništavilo, a religija se hrani ovom strepnjom (Kuljić, 2014: 15). Prema verovanjima unutar katoličke tradicije, telesna smrt ne predstavlja kraj života (Braun, 2000: 48), a isto verovanje prisutno je i u pravoslavnom učenju. U srcu hrišćanstva leži verovanje u Hristovo uskrsnuće i mogućnost da, kroz veru u Hrista, čovečanstvo uskrsne u večni život. Kada se smrt posmatra kao prelazna tačka ka večnom životu, može se lakše prihvatiti (Braun, 2000: 84). Prema zapadnim sistemima verovanja, postoji život posle smrti, a koncept „lične besmrtnosti” osnovno je verovanje unutar hrišćanske tradicije (Kastenbaum, 2003: 456, 458). Prema nekim mišljenjima, strah od smrti i verovanje u život nakon smrti predstavljaju univerzalni fenomen (Berta, 2003: 13). Verovanje u besmrtnost i produženje života u večnosti jedna je od najkompleksnijih i najspecifičnijih odbrana od straha, karakteristična za zapadnu civilizaciju od njenih početaka sve do današnjih dana (Erić, 2001: 87).

- postojanje Sudnjeg dana, raja i pakla

Sudnji dan je dan na koji će mrtvi biti pozvani da im se sudi, i biti večno nagrađeni ili osuđeni. $U$ trenutku smrti ljudima se sudi na osnovu načina na koji su živeli (Braun, 2000: 84). Hrišćanska vera vrlo uzdržano govori o raju i paklu, kao mestima na koja duša može otići nakon Sudnjeg dana. Raj je mesto blaženstva, dok pakao predstavlja mesto muka i patnje (Matić, 2013: 15, 27). Dakle, prema hrišćanskom učenju, zagrobni život postoji u dvama različitim svetovima - u raju i paklu. Pravednici posle smrti nastavljaju da žive u raju, a grešnici odlaze u pakao, gde su izloženi mnogim mučenjima (Zečević, 2007: 30). Prema katoličkoj doktrini, život se ne završava telesnom smrću, već tada duša napušta telo i odlazi u raj, čistilište ili pakao (Braun, 2000: 48), dok prema pravoslavnoj doktrini odlazi u raj ili pakao, jer čistilište je pojam koji se vezuje isključivo za katoličanstvo. 
- $\quad$ raj se nalazi gore, na nebu

Mitovi i legende o Isusovom uskrsnuću vezuju se za mit o Carstvu nebeskom, u koje će, nakon smrti, stupiti svi hrišćanski pravednici (Vukomanović, 1992: 119). Hrišćanska učenja usadila su ideju o ponovnom susretu sa voljenim osobama nakon završetka ovozemaljskog života $i$ odlaska na nebo (Kastenbaum, 2003: 458). Nakon odlaska u raj, oni se ponovo sastaju, tj. sjedinjuju, u životu koji ih čeka nakon smrti. Na nebu sledi susret sa Bogom $\mathrm{i}$ sa svecima.

***

Verovanje u život posle smrti nalazi se u osnovi metafore SMRT JE VEČNI ŽIVOT. U španskom jeziku pronalazimo sledeće izraze, tj. jezičke realizacije, u kojima su sadržane metafore:

- Ir a la vida eterna ('ići u večni život');

- descansar en la Gloria eterna ('počivati u večnoj slavi');

- dormir el sueño eterno ('spavati večnim snom').

U srpskom jeziku takođe pronalazimo primere kao što su:

- $\quad$ otići u večni mir;

- $\quad$ zaspati večnim snom / počinuti večnim snom;

- ićilotići na večni počinak;

- $\quad$ ići na večno počivalište.

Deo ove metafore čine pojave kao što je susret sa Bogom i sa svecima nakon smrti, a taj susret događa se nakon odlaska, tj. uspinjanja, na nebo, gde se nalazi raj, što se ogleda u izrazu:

- $\quad$ ascender a los cielos ('popeti se na nebo'). Ova metafora jeste i primer prostorne metafore VEČNI ŽIVOT JE GORE.

Verovanje u susret sa Bogom i sa svecima nakon smrti u osnovi je metafore SMRT JE UNIJA/SJEDINJAVANJE SA BOGOM, što vidimo u izrazu:

- reunirse con el Creador ('sjediniti se sa Tvorcem').

Čovekova telesna, prolazna egzistencija završava se trenutkom upokojenja. U srednjem veku samrtni čas manje je shvatan kao kraj, a više kao novi početak, koji nagoveštava najvažniju etapu ljudskog bitisanja - obitavanje u budućem veku, tj. večni život u Hristu (Popović, 2011: 163).

Odlazak na nebo i susret sa Bogom predstavlja Sudnji dan, kada se ljudskoj rasi sudi za život koji je vodila na zemlji:

- $\quad$ ser llamado a juicio ('biti pozvan na suđenje'). 
Prema hrišćanskom učenju, zagrobni život postoji u dvama različitim svetovima - u raju i paklu. Pravednici posle smrti nastavljaju da žive u raju, a grešnici odlaze u pakao. Slična shvatanja bila su poznata i mnogim drugim dualističkim religijama, čije je osnovno učenje borba dobra i zla. Hrišćanstvo je te koncepcije sintetizovalo i prilagodilo svojim potrebama (Zečević, 1982: 25).

Viđenje smrti kao zasluženog odmora nakon brojnih patnji u ovozemaljskom životu, tj. odmora koji donosi spokojstvo i mir (večni san), nalazi se u osnovi metafore SMRT JE SAN/ODMOR. Pronalazimo i srpske i španske izraze (koji sadrže metaforička preslikavanja) koji prikazuju smrt kao san ili odmor, tj. postoji niz izraza u obama jezicima u kojima je smrt konceptualizovana kao spavanje odnosno odmor. U srpskom jeziku pronalazimo sledeće primere:

- zaspati;

- zaspati večnim snom;

- ićilotići na večni počinak;

- počinuti večnim snom;

- ići na večno počivalište;

- upokojiti se;

- $\quad$ počivati u miru (božjem);

- otići u večni mir.

U španskom jeziku pronalazimo primere:

- descansar/reposar ('počivati', 'odmarati se');

- descansar en paz / en la paz del Señor ('počivati u miru / u miru božjem');

- descansarldormir en el Señor ('upokojiti se u Gospodu');

- dormir en Dios ('upokojiti se u Bogu');

- descansar en la Gloria eterna ('počivati u večnoj slavi');

- dormir el sueño eterno ('spavati večnim snom');

- dormir el sueño de los justos ('spavati snom pravednika');

- descansar en tierra santa ('počivati u Svetoj zemlji').

Osnovu za metaforu SMRT JE SAN/SPAVANJE predstavlja naše znanje o fiziološkim efektima smrti, jer u ovim metaforama nailazimo na korespondencije (preslikavanje) između izvornog i ciljnog domena, tj. između osobe koja spava $\mathrm{i}$ mrtve osobe. To se dešava jer postoji određena korespondencija između fizioloških efekata smrti i efekata spavanja; kako navodi Tian (2014: 138), to su sledeće sličnosti:

entiteti koji spavaju mirni su i leže - efekat spavanja je mirnoća i ležanje; 
$>\quad$ entiteti koji su mrtvi mirni su, ne pomeraju se, tj. leže - efekat smrti je mirnoća i ležanje.

Izrazi u kojima je smrt u obama jezicima konceptualizovana kao spavanje temelje se na korespondenciji koja podrazumeva, u obama slučajevima, jedan oblik stanja bez svesti. Zbog čega su ove metafore hrišćanski motivisane? Fernandes (Fernández, 2006: 121) ističe da je ovo mapiranje zasnovano na činjenici da su odmor i spavanje privremeni, i stoga se smrt konceptualizuje kao privremeni događaj. Ova analogija podrazumeva da prestanak telesnih funkcija i govora nije automatski identifikovan sa simptomima fizičke smrti, jer je prisutan i u mirnom snu. Konceptualizacija koja povezuje smrt sa odmorom ili snom/spavanjem predstavlja eufemistički pristup temi smrti, kao tabu temi, uglavnom zato što ova asocijacija na kraju vodi ka poricanju smrti kao takve. To znači da umiruća osoba više nije mrtva, već je utonula u utešni san. Hrišćani koriste ovu metaforu da se uteše kada neko umre i da označe da se mrtvi odmaraju od zemaljskih obaveza. U pitanju je poricanje smrti, jer se pretpostavlja da se mrtva osoba negde odmara ili da spava, i prestaje da pati i da se muči u ovozemaljskom životu (Fernández, 2006: 121), što se jasno vidi u sledećoj metafori za smrt:

\section{- dejar de sufrir ('prestati patiti').}

Kod metafore u kojoj se smrt poredi sa odmorom poreklo korespondencije između odmora i smrti leži u tome što se u okviru konceptualne metafore SMRT JE ODMOR smatra da smrt pruža neku vrstu olakšanja, a samim tim i odmora umirućoj osobi, na čemu se i zasniva ovo mapiranje, kao i njegova eufemistička sila.

Smrt je, bez sumnje, predstavljala trajnu i veoma važnu preokupaciju još za života čovekovog. Stoga je glavni zadatak svakog pravog hrišćanina bila temeljna priprema za trenutak odlaska (Popović, 2011: 163), a čin napuštanja ovog sveta, ili možda bolje reći - umeće umiranja kod Srba u srednjem veku nije se bitno razlikovalo od situacije karakteristične za druge evropske hrišćanske narode (Popović, 2011: 164). Hrišćanska tradicija smrt naziva „krajem hodočasnog stanja osobe”, ili „krajem putovanja osobe”. Celokupan se život, u određenom smislu, posmatra kao priprema za smrt, koja predstavlja prestanak odgovornosti osobe za oblikovanje sopstvenog zemaljskog života i rada na dostizanju spasenja kroz milost božju (Braun, 2000: 84). Ovo uverenje u osnovi je metafore SMRT JE PUTOVANJE/ODLAZAK, koja predstavlja slikovnu šemu. Destinacija putovanja za hrišćanske vernike jeste raj, tj. nebo. Prema tome, umiranje se konceptualizuje kao putovanje na nebo, tj. u raj. 
U srpskom jeziku pronalazimo sledeće primere:

- otići;

- otićilproći život;

- otići na drugi svet;

- napustiti ovaj svet;

- otićilići Bogu na istinu;

- otići pod crnu zemlju;

- rastati se sa životom/dušom;

- oprostiti se sa životom / s ovim svetom;

- rasta(vi)ti se sa ovim svetom / od ovoga sveta;

- putovati, preseliti se u večnost;

- ićilotići na večni počinak;

- ići na večno počivalište;

- otići u večni mir;

- otići u grob.

Brojni su i primeri na španskom jeziku:

- irse / irse prematuramente ('otići / prerano otići');

- irse al hoyo ('ići/otići u grob');

- irse de viaje ('otići na put');

- ser el viaje último de alguien ('biti nekome poslednje putovanje');

- hacer el último viaje ('otići na poslednje putovanje');

- irse al otro mundo / al otro barrio ('otići na drugi svet');

- mudarse a un mejor barrio ('preseliti se u bolji kraj');

- $\quad$ irselsalir de este mundo ('otići sa ovog sveta');

- abandonar este mundo ('napustiti ovaj svet');

- irselvolar al cielo ('otići/odleteti na nebo');

- irse a la Gloria ('ići u slavu');

- pasar a mejor vida ('otići u bolji život');

- dejar a alguien ('napustiti nekog');

- partir(se) alguien de esta vida ('rastati se od života').

Kroz metaforu SMRT JE PUTOVANJE umiranje je koncipirano kao putovanje životnom stazom od polazne tačke do kraja. Lejkof (Lakoff, 1987: 275) navodi da kompleksni događaji imaju inicijalna stanja (izvor), sekvencu faza koje dolaze između (putanja) i konačno stanje (odredište). Ovo konceptualno iskustvo strukturirano je u vidu slikovne šeme izvor-put-cilj/destinacija (engl. Source- 
Path-Goal), koja predstavlja osnovu za seriju metaforičkih mapiranja iz ovog prostornog domena u apstraktni domen kao što je smrt. Ova slikovna šema temelji se na telesnom iskustvu: svaki put kad krenemo bilo gde, postoji mesto odakle krećemo, mesto na kom će se završiti to kretanje, ali i niz usputnih lokacija koje povezuju početnu i krajnju tačku kretanja. Život se može shvatiti kao proces sa početnom i krajnjom tačkom i vremenskim rasponom. Metaforičko shvatanje prolaska vremena zasnovano je na kretanju po fizičkom putu, i mi razumemo tok procesa uopšte metaforički kao kretanje po putu ka nekoj krajnjoj tački. Tako se ljudski život karakteriše kao proces, i kao takav ograničen je šemom izvor-put-cilj, tako da se smatra da ima početnu tačku, krajnju tačku i vremenski period između. Na taj način, smrt se može koncipirati kao poslednji momenat $u$ našem vremenskom periodu, kroz metaforu SMRT JE POSLEDNJI ČAS. U srpskom i španskom jeziku pronalazimo sledeće primere:

- kucnuti nekome poslednji (samrtni) čas;

- llegarle a alguien la hora / su hora / su última hora ('stići nekom čas / poslednji čas').

Lejkof i Tarner (Lakoff-Turner, 1989: 8) navode da je ova metafora, tj. slikovna šema, aktivirana od strane metafore SMRT JE ODLAZAK NA KONAČNU DESTINACIJU, tj. SMRT JE POSLEDNJE PUTOVANJE. Iz ove perspektive, smrt je koncipirana kao poslednja faza našeg životnog veka, pomoću metafore SMRT JE KRAJ. Prolazak vremena na kraju će dovesti do smrti, pa se zbog toga javljaju metafore koje se fokusiraju na krajnju tačku tog procesa, kroz metaforu SMRT JE KRAJ, kao i na rezultat, koji predstavlja nestanak sa ovog sveta. U srpskom jeziku pronalazimo sledeće izraze koji ilustruju ovu ideju:

- doći / približiti se kraj;

- raskinuti sa životom;

- kucnuti nekome poslednji (samrtni) čas;

- ispustiti poslednji dah;

- poslednji dug Bogu platiti.

Brojni su primeri koje smo pronašli u španskom jeziku:

- llegarle a alguien la hora / su hora / su última hora ('kucnuti nekom čas / poslednji čas');

- llegarle a alguien el fin de sus días ('doći nekome kraj njegovih/njenih dana');

- terminarlacabar la vida de alguien ('završiti se nečiji život');

- dar fin ('završiti', 'umreti'); 
- dar fin a la vida de alguien ('okončati/završiti nečiji život');

- llegar el término de vida ('stići kraj života');

- exhalar el último aliento ('izdahnuti', 'ispustiti poslednji dah').

Kod Srba je bilo rašireno mišljenje da duša napušta telo kao pramičak magle u poslednjem dahu. Zato se i danas za čoveka koji je umro kaže da je „izdahnuo”, „ispustio dušu” (Zečević, 1982: 11). Ovu ideju pronalazimo u obama jezicima, pa je ekvivalent srpske metafore ispustiti poslednji dah metafora na španskom jeziku exhalar el último aliento ('izdahnuti', tj. 'ispustiti poslednji dah').

\section{ZAKLJUČAK}

U skladu sa ciljem ovog rada - da osvetlimo fenomen smrti u španskoj i srpskoj tradiciji i kulturi - analizirali smo metafore o smrti i umiranju, obraćajući posebnu pažnju na religijski aspekt. Prikazali smo načine na koje se smrt i umiranje metaforički konceptualizuju u ovim dvama jezicima, putem sistema metafora utemeljenih na našem telesnom i društvenom iskustvu. $\mathrm{Na}$ osnovu analize odabranog korpusa uočili smo brojna poklapanja i ista mapiranja (preslikavanja), kao i slične načine konceptualizacije smrti i umiranja, konstruisane oko motiva hrišćanske religije u srpskom i španskom jeziku.

Analiza metafora o smrti i umiranju upućuje na to da su navedena metaforička mapiranja za smrt istovremeno i mapiranja utemeljena na hrišćanskom sistemu verovanja (verovanja u besmrtnost, tj. večni život, postojanje raja i pakla, Sudnji dan, Boga kao Stvaraoca koji je na nebu itd.). Upravo ova verovanja pružaju osnovu za niz metaforičkih izraza koji su zajednički obama jezicima, tj. narodima, i nalaze se u osnovi metafora: SMRT JE VEČNI ŽIVOT, SMRT JE UNIJA/SJEDINJAVANJE SA BOGOM, SMRT JE SAN/ODMOR, SMRT JE PUTOVANJE/ODLAZAK i SMRT JE KRAJ. Analizirane metafore o smrti i umiranju oslanjaju se na hrišćanska uverenja, što je i bila pretpostavka autorke rada. Većina izraza o smrti (koji sadrže metaforička preslikavanja) zasniva se na hrišćanskoj nadi da će oni koji su umrli otići na nebo, tj. u raj, i živeti večno, da će se sastati, tj. sjediniti, sa Bogom/Stvaraocem, da će nakon smrti preći u „bolji svet” i u raju se odmoriti od ovozemaljskog života. Možemo reći da je hrišćanska religija motivisala pozitivan pogled na smrt. Metafore o smrti i umiranju u srpskom i španskom jeziku predstavljaju eufemističke zamene, jer se o smrti ne govori direktno, što pokazuje da se smrt, iz straha, konceptualizovala kao tabu. Ove metafore koriste se s ciljem da uteše ljude zbog gubitka neke osobe i pomognu im 
da se suoče sa gubitkom, time što poručuju da se osoba koja je umrla odmara od ovozemaljskog života i muka, prešavši u večni život, koji sledi nakon smrti.

Analiza korpusa ukazala je na uticaj hrišćanske religije na načine metaforičke konceptualizacije fenomena smrti u španskom i srpskom jeziku. $\mathrm{S}$ obzirom na to da oba naroda pripadaju evropskom kontekstu i hrišćanskoj tradiciji i kulturi, ostaje pitanje da li možemo zaključiti da postoji univerzalni karakter metaforičkih mapiranja koja smo pronašli u obama jezicima. Kako navodi Lejkof (Lakoff, 1994), neka su mapiranja univerzalna, dok su druga karakteristična za određenu kulturu, tj. kulturno uslovljena, pa su zbog toga neophodne i kontrastivne studije koje bi ove jezike poredile sa jezicima koji ne pripadaju judeo-hrišćanskoj tradiciji. Takva istraživanja mogla bi da upute na različita mapiranja, tj. različite konceptualizacije, kada je fenomen smrti u pitanju, što predstavlja i smernice za buduća istraživanja na ovu temu.

Ivana Georgijev

\section{METAPHORS ON DEATH AND DYING IN SPANISH AND SERBIAN}

\section{Summary}

The aim of this paper is to highlight the phenomenon of death in Spanish and Serbian traditions and cultures by comparing metaphors on death and dying. The author aims to identify metaphorical mappings in these two languages, as well as to detect the ways of metaphorical conceptualization of the phenomenon of death. We proceeded from the assumption that a common Christian tradition (Orthodox in Serbian and Catholic in Spanish case) had influenced the way of Serbian and Spanish conceptualization of death. The same or similar religious traditions could reveal certain similarities in the contrastive analysis of the metaphors on death and dying.

The paper relies on the postulates of cognitive linguistics and the theory of conceptual metaphor. A metaphor represents the main mechanism in cognitive linguistics which allows us to understand abstract concepts and phenomenons we cannot see or touch. When the topic of death is concerned, it finds its place in cognitive linguistics because death is one of the biggest concerns of peope, seen as the biggest mystery of all, although, at the same time, we do not want to think too much about it.

The analysis suggests that metaphorical mapping for death are based on the Christian religious belief system (beliefs about immortality, eternal life, existence of Paradise and Hell, Judgment Day, God as the Creator...). These beliefs provide the basis for a series of metaphorical expressions that are common in both languages and cultures. These beliefs are form the basis of the metaphors: DEATH IS THE ETERNAL LIFE, DEATH IS A UNION / A MEETING WITH GOD, DEATH IS A DREAM / A REST', DEATH IS A TRAVEL / A 
DEPARTURE AND DEATH IS THE END. These results do not surprise us bearing in mind that both nations belong to the European context and Christian traditions and cultures, nevertheless the question of the existence of the universal character of metaphorical mapping, that we found in both languages, still remains. The guidelines for some future research on this subject could be contrastive studies that would compare these languages with other languages that do not belong to the Jewish-Christian tradition.

Key words: metaphor, death, religion, Spanish language, Serbian language

\section{LITERATURA}

Berta, P. (2003). Anthropological Perspective. In: Kastenbaum, R. (ed.) (2003). Macmillan Encyclopedia of Death and Dying, Vol 1. New York: Macmillan Reference USA. 26-29.

Braun, S. F. (2000). Hrišćanstvo. Beograd: Čigoja štampa.

Drobnjak, D., Gudurić, S. (2011). Frazemi iz semantičkog polja „smrt” u francuskom i srpskom jeziku. Zbornik Matice srpske za filologiju $i$ lingvistiku, LIV (2), 237-246.

Erić, Lj. (2001). Strah od smrti. Niš: Prosveta.

Fernández, C. (2006). The language of Death: Euphemism and Conceptual Metaphorization in Victorian Obituaries. Sky Journal of Linguistics, 19, 101-130.

Johnson, M. (1987). The Body in the Mind. Chicago: University of Chicago Press.

Kastenbaum, R. (2003). Immortality. In: Kastenbaum, R. (ed.) (2003). Macmillan Encyclopedia of Death and Dying, Vol 1. New York: Macmillan Reference USA. 456-461.

Klikovac, D. (2004). Metafore u mišljenju i jeziku. Beograd: XX vek.

Kovačević, I., Sinani, D. (ured.) (2014). Antropologija smrti ili nova antropogija i religijski kompleks vezan za smrt. Etnoantropološki problemi, 9 (4), 10551072.

Kövecses, Z. (2005). Metaphor in Culture: Universality and Variation. Cambridge, New York: Cambridge University Press.

Kövecses, Z. (2010). Metaphor. A Practical Introduction. 2nd edition. Oxford: Oxford University Press.

Kövecses, Z. (2015). Where Metaphors Come From: Reconsidering Context in Metaphor. Oxford: Oxford University Press.

Kuljić, T. (2014). Tanatopolitika: sociološkoistorijska analiza političke upotrebe smrti. Beograd: Čigoja. 
Lakoff, G., Johnson, M. (2003 [1980]). Metaphors we live by, 2nd edn. Chicago: Chicago University Press.

Lakoff, G., Turner, M. (1989). More Than Cool Reason: A Field Guide to Poetic Metaphor. Chicago: University of Chicago Press.

Lakoff, G. (1987). Women, Fire and Dangerous Things. Chicago: University of Chicago Press.

Lakoff, G. (1994). The Contemporary Theory of Metaphor. In: Ortony, A. (ed.) (1994). Metaphor and Thought. Cambridge: Cambridge University Press. 202-251.

Matić, T. (2013). Kult mrtvih kod Srba. Beograd: Albatros plus.

Opašić, M., Gregorović, M. (2010). Smrt u hrvatskoj frazeologiji. Croatica et Slavica Iadertina, 6 (6), 55-72.

Palajsa-Backović, K. (2012). Eufemizmi u čituljama crnogorske dnevne štampe. Lingua Montenegrina, 5/1 (9), 39-50.

Popović, M. (2011). Srednjovekovna epoha. U: Popović, M., Timotijević, M. \& Ristović, M. (2011). Istorija privatnog života u Srba: od srednjeg veka do savremenog doba. Beograd: Clio. 19-170. (štampano ćirilicom)

Tian, C. (2014). A Contrastive Study of Death Metaphors in English and Chinese. International Journal of English Linguistics, 4 (6),134-142.

Vukomanović, M. (1992). Rani hrišćanski mitovi. Hermeneutička ispitivanja. Beograd: Naučna knjiga.

Wendell Moller, D. (2003). Taboos and Social Stigma. In: Kastenbaum, R. (ed.) (2003). Macmillan Encyclopedia of Death and Dying, Vol 1. New York: Macmillan Reference USA. 871-873.

Zečević, S. (2007). Kult mrtvih kod Srba. Beograd: Službeni glasnik.

Zečević, S. (1982). Kult mrtvih kod Srba. Beograd: Vuk Karadžić, Etnografski muzej. (štampano ćirilicom)

\section{IZVORI}

Cantera Ortiz de Urbina, J., Gomis Blanco, P. (2007). Diccionario de fraseología española: locuciones, idiotismos, modismos y frases hechas usuales en español. Madrid: Abada Editores.

Otašević, Đ. (2012). Frazeološki rečnik srpskog jezika. Novi Sad: Prometej. (štampano ćirilicom)

Real Academia Española. (2001). Diccionario de la lengua española (22. ${ }^{\mathrm{a}}$ ed.). Preuzeto 15. maja 2018, sa http://lema.rae.es/drae/ 
Real Academia Española: Banco de datos (CORDE) [on-line]. Corpus diacrónico del español. Preuzeto 15. maja 2018, sa http://www.rae.es/recursos/bancode-datos/corde

RSJ: Rečnik srpskoga jezika. Novi Sad: Matica srpska, 2007. (štampano ćirilicom) 
РУСИНИСТИКА 
